\title{
Optimizing the planting structure in Daxing District in 2020 based on inaccurate two-stage planning model and grey model
}

\author{
Zhipeng Wang ${ }^{1}$,Wei Dai ${ }^{1}$,Yuan $\mathrm{Shi}^{1, \mathrm{a}}{ }^{\text {,Meijian Bai }}{ }^{1}$,Qunchang Liu ${ }^{1}$ and Xin Zeng ${ }^{2}$ \\ ${ }^{1}$ China Institute of Water Resources and Hydropower Research,100048 Beijing,China \\ ${ }^{2}$ Water Recourses and Hydropower Planning and Design General Institute,100120 Beijing,China
}

\begin{abstract}
In order to optimize the planting structure and use water more efficiently, an inaccurate two-stage planning model is proposed in this paper. This model can not only reflect uncertainty of the probability distribution in the form of the possible distribution interval, but also build a recourse relationship between expected benefits and penalties for failing to achieve target goals. The two-stage planning model, combined with the gray GM (1.1) model, is applied to Daxing district of Beijing to optimize and adjust planting areas of the grain crops, fruits and vegetables, and garden plots in 2020. In the meantime, three scenarios were established for comparative analysis. Results show that after optimization, the economic benefits of above-mentioned three planting areas in Daxing district in 2020 is 3.71 billion CNY, an increase of 348 million from $2016 \mathrm{CNY}$; the total water consumption is 64.17 million cubic meters, a decrease of 62.79 million cubic meters from 2016. Results indicate that this model method is feasible for optimizing planting structure, and to some extent, can provide decision-making support and a theoretical basis for planting structure optimization and prediction in similar areas to Daxing district.
\end{abstract}

\section{Foreword}

Water is the lifeblood of agriculture. According to statistics, agricultural water consumption accounts for $70 \%$ to $80 \%$ of China's total water use, while planting accounts for $85 \%$ of agricultural water use ${ }^{[1]}$. Therefore, it is necessary to optimize the planting structure so as to use agricultural water resources efficiently.

Most of the early adjustments of planting structure focused on optimizing a single objective. For example, $\mathrm{Xu}^{[2]}$ constructed a planting structure optimization model with the goal of maximizing economic benefits; Wang ${ }^{[3]}$ made optimization with the goal of maximizing grain output. Afterwards, with the emergence of the sustainable development of agricultural resources, the original single-objective optimization cannot meet multiple planting requirements. Gradually, a model with multiple objectives of economic, ecological and social benefits was formed. For example, Tang et $\mathrm{al}^{[4]}$ proposed a multi-objective model and used entropy weight coefficient method to determine the weight so as to construct a model method for solving multi-objective problems using the product of subjective weight and objective weight; Chen et al ${ }^{[5]}$ proposed fuzzy weighting and constructed a multi-objective model of planting structure; $\mathrm{Wu}$ et $\mathrm{a}^{[6]}$, taking into account the economic benefits of grain water, proposed a gray multi-objective planning model; Li et $\mathrm{al}^{[7]}$ constructed a multi-objective

\footnotetext{
a Corresponding author: 86091263@qq.com
}

optimization model based on two-level fractional programming, with comprehensive benefits of upper the lower layer planting as the goal, while taking into consideration the suggestions offered by the upper and lower managers. The multi-objective model of planting structure changes the model featuring pure pursuit of economic benefit, takes into account the benefits of multi-party during the process of optimization, and is conducive to the sustainable development of water and agricultural resources.

Optimizing agricultural planting structure is a complex and inaccurate problem. Uncertainties of the environment and model parameters affect the optimization results. Most of the abovementioned models focus on only the target benefits, but fail to cover the uncertainties in the model. The inaccurate two-stage planning model proposed in this paper is based on a two-stage stochastic model and is combined with an interval parameter model. It can not only reduce the uncertainty in planning and express it as a certain interval number, but also establish an effective recourse relationship between expected benefits and penalties for failing to achieve target goals so as to minimize the potential loss in the first stage of decision making. Previously, the model was mostly adopted as a solution to water resources planning ${ }^{[8]}$. This paper applies the model to optimize planting structure and adjust the planting area of grain crops, fruits and vegetables, and garden plots in Daxing district. This paper calculated economic benefits in three proposed planning scenarios, 
comprehensively compared the water consumption, and came up with the corresponding adjustment plans of planting structure in different scenarios so as to obtain optimal optimization results.

\section{Introduction to the method}

\subsection{Two-stage stochastic model}

The two-stage stochastic model and its recourse rights reflect the decision making in the first stage and coordination relationship between decision and its consequent effects. The model is as follows ${ }^{[9]}$ :

$$
\max f=c x-\mathrm{E}[\mathrm{Q}(x, \varepsilon)]
$$

Constraints:

$$
\begin{gathered}
A x \leq b \\
x \geq 0
\end{gathered}
$$

$\varepsilon$ is the random variable of the second stage; $x$ is the decision made in the first stage before $\varepsilon$ is set; $\mathrm{Q}(x, \varepsilon)$ is the optimal value of the following nonlinear programming:

$$
\operatorname{minq}(y, \varepsilon)
$$

Constraints:

$$
\begin{gathered}
\mathrm{W}(\varepsilon) y=\mathrm{h}(\varepsilon)-\mathrm{T}(\varepsilon) x \\
y \geq 0
\end{gathered}
$$

$y$ is the adaptive decision in the second stage depending on the realization of the random variable $\varepsilon$; $\mathrm{q}(y, \varepsilon)$ represents the cost function in the second stage; $\{\mathrm{T}(\varepsilon), \mathrm{W}(\varepsilon), \mathrm{h}(\varepsilon) \mid \varepsilon \in \Omega\}$ represents a stochastic model parameter of random variable $\varepsilon$ within a certain range.

In the first stage, decision is made before the random variable $\varepsilon$ is obtained. But when $\varepsilon$ is obtained, there might be a corresponding difference between $\mathrm{h}(\varepsilon)$ and $\mathrm{T}(\varepsilon) x$. At this point, minimize $\mathrm{q}(y, \varepsilon)(\mathrm{W}(\varepsilon) y=\mathrm{h}(\varepsilon)-\mathrm{T}(\varepsilon) x$, $y \geq 0)$ so as to correct it. This kind of recourse can take into account both the pre-efficiency and the potential penalties arising from decision making in the first stage. Therefore, model (1) can be rewritten as follows: $\max f=c x-\mathrm{E}\{\min [\mathrm{q}(y, \varepsilon) \mid \mathrm{T}(\varepsilon) y+\mathrm{W}(\varepsilon) y=\mathrm{h}(\varepsilon)]\}$

Constraints:

$$
\begin{gathered}
A x \leqslant b \\
x \geqslant 0 \\
y \geq 0
\end{gathered}
$$

To make calculation easier and reduce error, take the discrete value $\varepsilon_{l}$, and the corresponding probability is $p_{l}(l=1,2, \ldots, n)$, while $p_{l}>0, \sum_{l=1}^{n} p_{l}=1$. Therefore, the optimization of the second stage can be expressed as the following form:

$$
E Q(x)=E[Q(x, w)]=\sum_{l=1}^{n} p_{l} Q\left(x, \varepsilon_{l}\right)
$$

Each discrete value $\varepsilon_{l}$ generates a corresponding decision in the second stage, which is defined as $y_{l}$. Therefore, the second stage can be further expressed as:

Constraints:

$$
\operatorname{minq}\left(y_{l}, \varepsilon_{l}\right)
$$

$$
\begin{gathered}
\mathrm{W}\left(\varepsilon_{l}\right) y_{l}=\mathrm{h}\left(\varepsilon_{l}\right)-\mathrm{T}\left(\varepsilon_{l}\right) x, \forall l=1,2, \ldots, n ; \\
y_{l} \geq 0
\end{gathered}
$$

Combine model (4) and (5), model (3) can be further expressed as:

$$
\max f=c x-\sum_{l=1}^{n} p_{l} q\left(y_{l}, \varepsilon_{l}\right)
$$

Constraints:

$$
\begin{aligned}
\mathrm{A} x & \leq \mathrm{b} \\
\mathrm{T}\left(\varepsilon_{l}\right) x+\mathrm{W}\left(\varepsilon_{l}\right) y_{l} & =\mathrm{h}\left(\varepsilon_{l}\right), \forall l=1,2, \ldots, n \\
x & \geq 0 \\
y_{l} & \geq 0
\end{aligned}
$$

Each symbol has the same meaning as before.

\subsection{Inaccurate two-stage stochastic model}

Although to some extent, the probability of distribution can be reflected in model (6), in real situations, not all useful information can be expressed as probability distribution $^{[8]}$. Therefore, the concept of interval parameter is introduced into the two-stage stochastic model in order to better reflect the uncertainty in the optimization process.

$x$ is a closed bounded real set, $x^{ \pm}$represents an interval with known upper and lower limits and unknown distribution information ${ }^{[10]}$ :

$$
x^{+}=\left[x^{-}, x^{+}\right]=\left\{t \in x \mid x^{-} \leq t \leq x^{+}\right\}
$$

$x^{-}$and $x^{+}$represent respectively the upper and lower limits of $x^{ \pm}$; when $x^{-}=x^{+}, x^{ \pm}$is a certain value.

By introducing the interval parameter model into the two-stage stochastic model, an inaccurate two-stage stochastic model is formed:

$$
\max f^{ \pm}=c^{ \pm} x^{ \pm}-\sum_{l=1}^{n} p_{i} q\left(y_{l}^{ \pm}, \varepsilon_{l}^{ \pm}\right)
$$

Constraints:

$$
\begin{aligned}
\mathrm{A}^{ \pm} x^{ \pm} & \leq \mathrm{b}^{ \pm} \\
\mathrm{T}\left(\varepsilon l^{ \pm}\right) x^{ \pm}+\mathrm{W}\left(\varepsilon l^{ \pm}\right) y l^{ \pm} & =\mathrm{h}\left(\varepsilon l^{ \pm}\right), \forall l=1,2, \ldots, n \\
x^{ \pm} & \geq 0 \\
y_{l}^{ \pm} & \geq 0
\end{aligned}
$$

Since $x^{ \pm}$is an uncertain input parameter, the above problem cannot be solved by a simple planning method ${ }^{[8]}$ Therefore, a decision variable $z$ is introduced into model (8) to express the target interval, as shown in model (9). To solve model (9), let $x=x^{-}+\Delta x z$, where $\Delta x=x^{+}-x^{-}, \quad z \in$ $[0,1]$.

$$
\max f^{ \pm}=c^{ \pm}\left(x^{-}+\Delta x z\right)-\sum_{l=1}^{n} p_{l} q\left(y_{l}^{ \pm}, \varepsilon_{l}^{ \pm}\right)
$$

Constraints:

$$
\begin{gathered}
\mathrm{A}^{ \pm}\left(x^{-}+\Delta x z\right) \leq \mathrm{b}^{ \pm} \\
\mathrm{T}\left(\varepsilon l^{ \pm}\right)\left(x^{-}+\Delta x z\right)+\mathrm{W}\left(\varepsilon l^{ \pm}\right) y l^{ \pm}=\mathrm{h}\left(\varepsilon_{l}^{ \pm}\right), \forall l=1,2, \ldots, n \\
\Delta x=x^{+}-x^{-} \\
x^{ \pm} \geq 0 \\
y_{l}^{ \pm} \geq 0 \\
0 \leq z \leq 1
\end{gathered}
$$

Model (9) can be converted into two sub-models, corresponding respectively to the upper and lower limits of the objective function value. This conversion process is based on interactive algorithm ${ }^{[11]}$. The sub-model corresponding to the upper limit target is as follows (assuming $\mathrm{c}^{ \pm}>0, \mathrm{~A}^{ \pm}>0$ and $\mathrm{b}^{ \pm}>0$ ): 


$$
\max f^{+}=c^{+}\left(x^{-}+\Delta x z\right)-\sum_{l=1}^{n} p_{l} q\left(y_{l}^{-}, \varepsilon_{l}^{-}\right)
$$

Constraints:

$$
\mathrm{A}^{-}\left(x^{-}+\Delta x z\right) \leq \mathrm{b}^{+}
$$

$\mathrm{T}\left(\varepsilon_{l}^{-}\right)\left(x^{-}+\Delta x z\right)+\mathrm{W}\left(\varepsilon_{l}^{-}\right) y_{l}^{-}=\mathrm{h}\left(\varepsilon_{l}^{-}\right), \forall l=1,2, \ldots, n$

$$
\begin{gathered}
\Delta x=x^{+}-x^{-} \\
y_{l} \geq 0 \\
0 \leq z \leq 1
\end{gathered}
$$

$z$ and $y_{l}{ }^{-}$are the decision variables. $z_{u}, y_{l U}{ }^{-}$and $f_{\mathrm{U}}{ }^{+}$is the solution to model (10), then the variable of optimization in the first stage is $x_{U}{ }^{ \pm}=x^{-}+\Delta x z$.

The corresponding lower limit sub-model is:

$$
\max f^{-}=c^{-} x_{U}^{ \pm}-\sum_{l=1}^{n} p_{l} q\left(y_{l}^{+}, \varepsilon_{l}^{+}\right)
$$

Constraints:

$$
\begin{gathered}
\mathrm{A}^{+} x_{U^{ \pm}} \leq \mathrm{b}^{-} \\
\mathrm{T}\left(\varepsilon_{l}^{+}\right) x_{U^{ \pm}+\mathrm{W}\left(\varepsilon_{l}^{+}\right) y_{l}^{+}}=\mathrm{h}\left(\varepsilon_{l}^{+}\right), \forall l=1,2, \ldots, n \\
x_{U^{ \pm}} \geq y_{l}^{+} \geq y_{U}^{+} \geq 0
\end{gathered}
$$

$y_{l}^{+}$is the decision variable, and assume $z_{u}, y_{l U}$ and $f_{\mathrm{U}}^{+}$ is the solution to this sub-model.

Therefore, the solution to model (9) in the first stage of optimization $\left(x_{U}^{ \pm}\right)$is:

$$
\begin{gathered}
f_{U}^{ \pm}=\left[f_{U^{-}}, f_{U}^{+}\right] \\
x_{U^{ \pm}}=x^{-}+\Delta x z_{U} \\
y_{l U}{ }^{ \pm}=\left[y_{l U^{-}}, y_{l U}^{+}\right], \forall l=1,2, \ldots, n
\end{gathered}
$$

\section{Application}

\subsection{Introduction to research area and model application}

Daxing district, Beijing, governing 14 towns, is located at $116^{\circ} 12^{\prime}-116^{\circ} 43^{\prime}$ east longitude and $39^{\circ} 26^{\prime}-39^{\circ} 50^{\prime}$ north latitude. It is a warm temperate zone with semi-humid continental monsoon climate with an annual average temperature of $11.6{ }^{\circ} \mathrm{C}$, an annual average evaporation of $1700 \mathrm{~mm}$, and an annual average precipitation of $556 \mathrm{~mm}$. Its precipitation is mainly concentrated in the months from June to September with large the annual variations ${ }^{[12]}$. Rivers in Daxing district are almost dried up, excluding a small number of transit sewage. Therefore, the source of irrigation water in Daxing district is mainly underground water, and $86 \%$ of the total groundwater extraction is used for irrigation ${ }^{[13]}$. In the past decade, the amount of groundwater exploitation in Daxing district has seriously exceeded the normal standard, as is shown in Figure 1. Therefore, it is of great significance to optimize the planting structure of the main crops in Daxing district in order to save water resources. The object selected for optimization in this paper is the planting area of grain crops, fruits and vegetables, and garden plots in Daxing district. Figure 2 shows the current (2016) planting structure. Due to the uneven distribution of underground water in Daxing district, the study area is divided into 14 districts based on the administrative district. The inaccurate two-stage stochastic model adopted in this paper can not only reflect uncertainty of the probability distribution in the form of the possible distribution interval, but also build a recourse relationship between expected benefits and penalties for failing to achieve target goals.

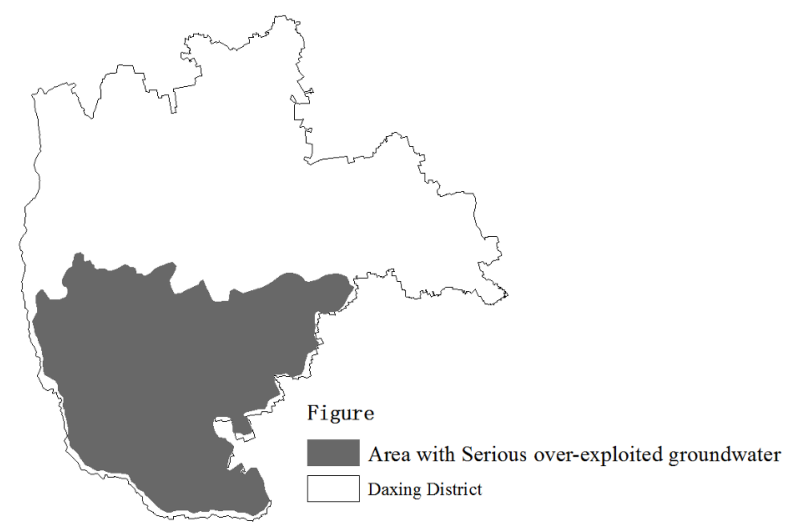

Figure 1 Area with serious over-exploited groundwater in Daxing district

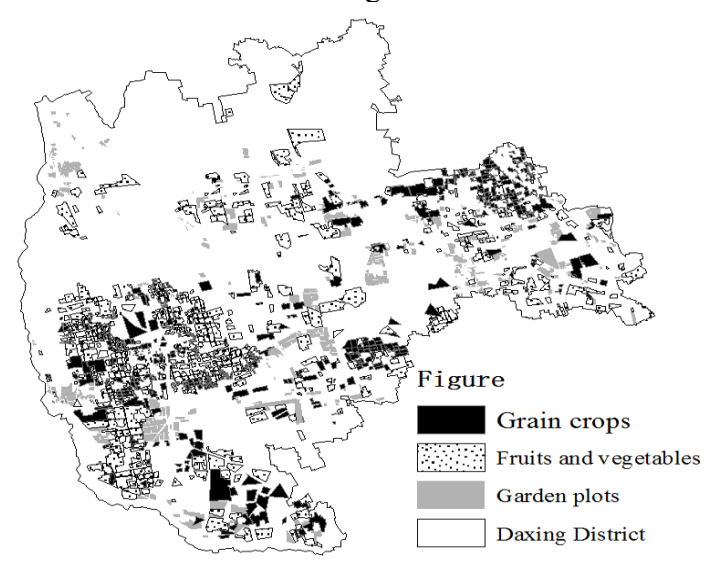

Figure 2 Status of planting structure in Daxing district in 2016

Three scenarios were established to obtain different optimization benefits while adjusting the planting structure in Daxing district. Comparative analysis can, to some extent, provide theoretical support and a decision-making basis for the study of regional benefit improvement.

The year of 2020 is selected as the year for optimization. Based on the statistics of crops in the past ten years in 2008 2017 Daxing District Statistical Yearbook, the yield per hectare of grain crops, fruits and vegetables, and garden plots in various sub-districts of Daxing district is obtained, as shown in Table 1. By consulting relevant references, the benefits of unit crop yield when Daxing district meets people's requirements and the penalties of corresponding unit crop yield when it fails to meet the requirements (see Table 2 for details). When the output produced by the planting area meets people's demand, corresponding economic benefits will be gained; on the contrary, when the output of the crop planting area fails to meet people's needs, it is necessary to purchase them by means of outsourcing, etc. That will increase the cost, which is called the penalties for failing to achieve target goals. Due to the uneven distribution of underground water and the large inter-annual variation in Daxing district, the amount of water available for irrigation is different every year. According to the crop yield in Daxing district in the past decade, the amount of water available is divided into four grades, namely 
extremely low, low, medium, and high. Corresponding probability is calculated, as is shown in Table 3.

Table 1 Yield per hectare of grain crops, fruits and vegetables, and garden plots in various sub-districts of Daxing district ( $\mathrm{kg} / \mathrm{ha})$

\begin{tabular}{|c|c|c|c|}
\hline District & $\begin{array}{l}\text { Grain } \\
\text { crops }\end{array}$ & $\begin{array}{l}\text { Fruits and } \\
\text { vegetables }\end{array}$ & $\begin{array}{l}\text { Garden } \\
\text { plots }\end{array}$ \\
\hline Yi Zhuang & 0 & 0 & 0 \\
\hline Huang Cun & $\begin{array}{c}{[5067.31,} \\
6964.18]\end{array}$ & $\begin{array}{c}{[23093.73,} \\
33198.66]\end{array}$ & $\begin{array}{l}{[21019.40,} \\
24219.85]\end{array}$ \\
\hline Jiu Gong & $\begin{array}{c}{[0,} \\
4062.99]\end{array}$ & $\begin{array}{c}{[0,} \\
18842.39]\end{array}$ & $\begin{array}{c}{[0,} \\
2184.48]\end{array}$ \\
\hline $\begin{array}{c}\mathrm{Xi} \\
\text { Hongmen }\end{array}$ & $\begin{array}{c}{[0,} \\
7018.36]\end{array}$ & $\begin{array}{l}{[14053.88,} \\
16817.91]\end{array}$ & $\begin{array}{c}{[0,} \\
20895.52]\end{array}$ \\
\hline Ying Hai & $\begin{array}{c}{[5816.57} \\
6036.12]\end{array}$ & $\begin{array}{l}{[32255.52,} \\
35611.79]\end{array}$ & $\begin{array}{c}{[0,} \\
20895.52] \\
\end{array}$ \\
\hline $\begin{array}{c}\text { Qing } \\
\text { Yundian }\end{array}$ & $\begin{array}{c}5427.01, \\
6388.06] \\
\end{array}$ & $\begin{array}{c}{[33306.27,} \\
38560.75]\end{array}$ & $\begin{array}{c}{[13701.19,} \\
16204.48]\end{array}$ \\
\hline Cai Yu & $\begin{array}{c}{[5804.78,} \\
6930.00]\end{array}$ & $\begin{array}{c}{[32040.90,} \\
43537.16]\end{array}$ & $\begin{array}{l}\text { [17728.51, } \\
22172.39]\end{array}$ \\
\hline An Ding & $\begin{array}{c}{[5765.97,} \\
6853.13]\end{array}$ & $\begin{array}{c}{[28786.87,} \\
52894.03]\end{array}$ & $\begin{array}{c}{[18186.87,} \\
26047.76]\end{array}$ \\
\hline Li Xian & $\begin{array}{l}\text { [6217.46, } \\
7032.99]\end{array}$ & $\begin{array}{l}\text { [33378.51, } \\
47616.12]\end{array}$ & $\begin{array}{l}{[12430.30,} \\
16468.21]\end{array}$ \\
\hline $\mathrm{Yu} \mathrm{Fa}$ & $\begin{array}{c}6053.58, \\
6761.19] \\
\end{array}$ & $\begin{array}{c}{[35865.67,} \\
50856.27]\end{array}$ & $\begin{array}{l}{[16630.00,} \\
25753.73]\end{array}$ \\
\hline $\begin{array}{c}\text { Pang } \\
\text { Gezhuang }\end{array}$ & $\begin{array}{c}{[5346.72,} \\
5697.61]\end{array}$ & $\begin{array}{c}{[49709.40,} \\
54154.48]\end{array}$ & $\begin{array}{c}\text { [14144.93, } \\
21147.16]\end{array}$ \\
\hline Bei Zang & $\begin{array}{c}5519.55, \\
6626.87]\end{array}$ & $\begin{array}{l}{[26031.34,} \\
39602.24]\end{array}$ & $\begin{array}{c}\text { [11025.22, } \\
12976.27]\end{array}$ \\
\hline $\begin{array}{c}\text { Wei } \\
\text { Gezhuang }\end{array}$ & $\begin{array}{c}{[5707.31,} \\
7092.69]\end{array}$ & $\begin{array}{c}{[31761.19,} \\
54212.99]\end{array}$ & $\begin{array}{l}\text { [15891.04, } \\
29782.09]\end{array}$ \\
\hline $\begin{array}{l}\text { Chang } \\
\text { Ziying }\end{array}$ & $\begin{array}{c}5492.54, \\
6602.39] \\
\end{array}$ & $\begin{array}{l}\text { [26824.48, } \\
36471.79]\end{array}$ & $\begin{array}{l}5193.43, \\
15903.13]\end{array}$ \\
\hline
\end{tabular}

Table 2 Benefits $d_{\mathrm{j}}^{ \pm}$and penalties $\mathrm{c}_{\mathrm{j}}^{ \pm}$of unit output in Daxing district

\begin{tabular}{|c|c|c|c|}
\hline & $\begin{array}{c}\text { Grain } \\
\text { crops }\end{array}$ & $\begin{array}{c}\text { Fruits and } \\
\text { vegetables }\end{array}$ & $\begin{array}{c}\text { Garden } \\
\text { plots }\end{array}$ \\
\hline $\begin{array}{c}\text { Benefit of unit } \\
\text { crop yield } d_{\mathrm{j}}^{ \pm} \\
(\mathrm{CNY} / \mathrm{kg})\end{array}$ & $\begin{array}{c}{[2.28,} \\
3.00]\end{array}$ & $\begin{array}{c}{[4.50,} \\
6.50]\end{array}$ & $\begin{array}{c}{[4.98,} \\
6.12]\end{array}$ \\
\hline & & & \\
$\begin{array}{c}\text { Penaltie of unit } \\
\text { crop yield cj } \\
(\mathrm{CNY} / \mathrm{kg})\end{array}$ & {$[3.11$,} & {$[5.60$,} & {$[6.04$,} \\
& $3.80]$ & $7.00]$ & $7.20]$ \\
\hline
\end{tabular}

Table $3 \mathrm{P}_{\mathrm{k}}$ : different yield probabilities in ten years

\begin{tabular}{|c|c|c|}
\hline Yield level & Probability $\left(\mathrm{P}_{\mathrm{k}}\right)$ & Yield $\left(\times 10^{8} \mathrm{~kg}\right)$ \\
\hline Extremely low & 0.09 & 0 \\
\hline Low & 0.17 & {$[0,6.96]$} \\
\hline Medium & 0.41 & {$[6.96,12.3]$} \\
\hline High & 0.33 & {$[12.3,14.04]$} \\
\hline
\end{tabular}

The population data of the sub-districts of Daxing district from 2007 2016 was obtained by consulting the 2008 2017 Yearbooks of Daxing District so as to forecast the demand for grain crops, fruits and vegetables, and garden plots in 2020. The smoothness test found out that the data fluctuations are small and in line with the quasi-index law. Therefore, the GM (1.1) model is used to predict the population, and further, the demand for grain crops, fruits and vegetables, and garden plots in the Daxing district in 2020. The results are shown in Table 4. Similarly, the agricultural water consumption of Daxing district in 2020 is $[64.71,70.62]$ million cubic meters. Based on the current arable area, the total arable land area in Daxing district is calculated, which is [33900, 36166.67] ha.

Table $4 n_{i j}^{ \pm}$: demand for grain crops, fruits and vegetables, and garden plots in sub-districts of Daxing district in $2020\left(\times 10^{3}\right.$ $\mathrm{kg}$ )

\begin{tabular}{|c|c|c|c|}
\hline District & $\begin{array}{l}\text { Grain } \\
\text { crops }\end{array}$ & $\begin{array}{l}\text { Fruits and } \\
\text { vegetables }\end{array}$ & $\begin{array}{c}\text { Garden } \\
\text { plots }\end{array}$ \\
\hline $\begin{array}{c}\text { Yi } \\
\text { Zhuang }\end{array}$ & $\begin{array}{c}{[19589.59,} \\
30410.51]\end{array}$ & $\begin{array}{l}{[7661.76,} \\
10222.88]\end{array}$ & $\begin{array}{l}{[1277.86,} \\
2555.72]\end{array}$ \\
\hline $\begin{array}{l}\text { Huang } \\
\text { Cun }\end{array}$ & $\begin{array}{c}{[36387.46,} \\
56487.21]\end{array}$ & $\begin{array}{c}{[14241.67,} \\
18988.81]\end{array}$ & $\begin{array}{c}{[2373.61,} \\
4747.22]\end{array}$ \\
\hline Jiu Gong & $\begin{array}{c}{[38325.93,} \\
59496.45]\end{array}$ & $\begin{array}{c}{[15000.36,} \\
2000.49]\end{array}$ & $\begin{array}{c}{[2500.06,} \\
5000.12]\end{array}$ \\
\hline $\begin{array}{c}\mathrm{Xi} \\
\text { Hongmen }\end{array}$ & $\begin{array}{c}{[48828.38} \\
75800.25]\end{array}$ & $\begin{array}{l}\text { [19110.91, } \\
25481.22]\end{array}$ & $\begin{array}{r}{[3185.15,} \\
6370.30]\end{array}$ \\
\hline Ying Hai & $\begin{array}{l}{[22668.52,} \\
35190.19]\end{array}$ & $\begin{array}{l}{[8872.22,} \\
11829.63]\end{array}$ & $\begin{array}{l}\text { [1478.71, } \\
2957.41]\end{array}$ \\
\hline $\begin{array}{c}\text { Qing } \\
\text { Yundian }\end{array}$ & $\begin{array}{l}{[25161.00,} \\
39059.46]\end{array}$ & $\begin{array}{l}{[9847.75} \\
13130.33]\end{array}$ & $\begin{array}{l}\text { [1641.29, } \\
3882.58]\end{array}$ \\
\hline Cai Yu & $\begin{array}{l}{[17949.75,} \\
27864.85]\end{array}$ & $\begin{array}{c}7025.34 \\
9367.12]\end{array}$ & $\begin{array}{l}{[1170.89,} \\
2341.78]\end{array}$ \\
\hline An Ding & $\begin{array}{l}{[14847.36,} \\
23048.76]\end{array}$ & $\begin{array}{l}\text { [5811.10, } \\
7748.13]\end{array}$ & $\begin{array}{l}\text { [968.52, } \\
1937.03]\end{array}$ \\
\hline Li Xian & $\begin{array}{c}{[19865.68,} \\
30839.11]\end{array}$ & $\begin{array}{l}{[7775.22,} \\
10366.96]\end{array}$ & $\begin{array}{l}{[1295.87,} \\
2591.46]\end{array}$ \\
\hline $\mathrm{Yu} \mathrm{Fa}$ & $\begin{array}{l}{[24575.93,} \\
38151.20]\end{array}$ & $\begin{array}{l}\text { [9618.76, } \\
12825.01]\end{array}$ & $\begin{array}{l}{[1603.13,} \\
3206.25]\end{array}$ \\
\hline $\begin{array}{c}\text { Pang } \\
\text { Gezhuang }\end{array}$ & $\begin{array}{l}{[25958.51,} \\
40297.49]\end{array}$ & $\begin{array}{c}{[10159.89,} \\
13546.51]\end{array}$ & $\begin{array}{l}\text { [1693.31, } \\
3386.63]\end{array}$ \\
\hline Bei Zang & $\begin{array}{l}\text { [7822.98, } \\
12144.24]\end{array}$ & $\begin{array}{c}{[3061.38} \\
4082.44]\end{array}$ & $\begin{array}{l}\text { [510.31, } \\
1020.61]\end{array}$ \\
\hline $\begin{array}{c}\text { Wei } \\
\text { Gezhuang }\end{array}$ & $\begin{array}{l}{[26757.46,} \\
41537.77]\end{array}$ & $\begin{array}{c}\text { [10472.59, } \\
13963.45]\end{array}$ & $\begin{array}{l}\text { [1745.43, } \\
3490.86]\end{array}$ \\
\hline $\begin{array}{l}\text { Chang } \\
\text { Ziying }\end{array}$ & $\begin{array}{l}{[13964.01,} \\
21677.47]\end{array}$ & $\begin{array}{c}{[5465.37} \\
7287.16]\end{array}$ & $\begin{array}{l}\text { [910.89, } \\
1821.79]\end{array}$ \\
\hline
\end{tabular}

The inaccurate two-stage planning model adopted in this paper can help to make the first-stage decision under the condition that the random variable in the second stage is unknown. It also helps to establish a recourse relationship between expected benefits and unknown penalties generated by the first-stage decision after the random variable is known. The optimization of the three kinds of crop areas in Daxing district is based on the allocation of planting area according to the predicted requirements of each crop $\left(n_{i j}^{ \pm}\right)$in each sub-district in 2020 and the yield per hectare of per crop in each sub-district $\left(k_{i j}^{ \pm}\right)$, under the condition of unknown total production. If the planting area meets the requirement, corresponding economic benefits are generated; if not, it is necessary to buy crops at a higher price, resulting in corresponding economic penalties. When the total crop yield is known, adjust the prior decision through the second-stage plan to minimize the penalty. In this way, an inaccurate two-stage planning model of crop planting 
structure with the goal of maximizing economic benefits is established. The model is as follows:

$$
\max f^{ \pm}=\sum_{i=1}^{14} \sum_{j=1}^{3} d_{j}^{ \pm} k_{i j}^{ \pm} a_{i j}^{ \pm}-\sum_{i=1}^{14} \sum_{j=1}^{3} \sum_{k=1}^{4} p_{k} c_{j}^{ \pm} s_{i j k}^{ \pm}
$$

Constraints:

$$
\begin{aligned}
& \sum_{i=1}^{14} \sum_{j=1}^{3} m_{i j}^{ \pm} a_{i j}^{ \pm} k_{i j}^{ \pm} \leq M^{ \pm}, \forall i, j \\
& \sum_{i=1}^{14} \sum_{j=1}^{3} a_{i j}^{ \pm}=A^{ \pm}, \forall i, j \\
& 0 \leq a_{i j}^{ \pm} \\
& s_{i j k}^{ \pm} \leq a_{i j}^{ \pm} k_{i j}^{ \pm}, \forall i, j, k \\
& 0 \leq s_{i j k}^{ \pm}, \forall i, j, k
\end{aligned}
$$

$f^{ \pm}$represents the overall economic benefits of Daxing district in 2020 (unit:CNY); $i$ represents each sub-division; $j$ represents the optimized crop; $k$ represents the grade of available water; $d_{j}^{ \pm}$refers to the unit yield benefit of each crop in each sub-district (unit: CNY/ kg); $k_{i j}{ }^{ \pm}$refers to the yield per unit area of each crop in each region (unit: $\mathrm{kg} / \mathrm{ha}$ ); $a_{i j}{ }^{ \pm}$represents the planting area of each crop in each sub-district in 2020 (unit: ha); $p_{k}$ refers to the probability of crop yield grade; $c_{j}^{ \pm}$refers to penalties received when each crop in each sub-district fails to meet people's demand (unit:CNY/ kg); $s i_{j k}{ }^{ \pm}$refers to the gap of amount when each crop in each sub-district fails to meet people's needs (unit: $\mathrm{kg}$ ); $m_{i j}{ }^{ \pm}$refers to the gross water consumption of each crop in each sub-district (unit: million cubic meters $/ \mathrm{kg}$ ); $\mathrm{M}^{ \pm}$refers to the agricultural water consumption in Daxing district in 2020 (unit: million cubic meters); $\mathrm{A}^{ \pm}$refers to the agricultural arable area in Daxing district in 2020 (unit: ha).

This model can reflect uncertainty of the probability distribution in the form of the possible distribution interval, and calculate probabilities based the production grade so as to minimize the penalty caused by the decision made in the first stage. For comparative analysis, the following three scenarios are established:

- Scenario 1, the maximum total crop yield in Daxing district meets people's demand: $\mathrm{N}^{ \pm}=\mathrm{N}^{+}$;

- Scenario 2, the minimum total crop yield in Daxing district meets people's demand: $\mathrm{N}^{ \pm}=\mathrm{N}^{-}$;

- Scenario 3, the average total crop yield in Daxing district meet people's demand: $\mathrm{N}^{ \pm}=\left(\mathrm{N}^{+}-\mathrm{N}^{-}\right) / 2$.

\subsection{Results}

The model is solved with MATLAB programming. The calculation results show that in scenario 1 , the economic benefit is $[2.59,4.61]$ billion CNY, the corresponding penalty is $[-0.15,-0.07]$ billion $\mathrm{CNY}$, and the water consumption is [66.02,70.55] million cubic meters; in scenario 2, the economic benefit is $[2.33,2.86]$ billion $\mathrm{CNY}$, the corresponding penalty is $[-0.24,-0.18]$ billion $\mathrm{CNY}$, and the water consumption is [37.58, 62.49] million cubic meters; in scenario 3 , the benefit is [3.12, 3.76] billion CNY, the corresponding penalty is $[-0.20$, -0.14] billion CNY, and the water consumption is [33.45, 64.17] million cubic meters. For details, see Figure 3 (the penalty will be taken as a positive value for convenience of observation). It can be seen that when the demand is high, the economic benefit and corresponding water consumption will be maximized; when the demand is low, the economic benefit and corresponding water consumption will be minimized. The penalties are negative because the fluctuation of the planting area in the Daxing district in the past decade is relatively great, so forecasted production in 2020 are more likely to be high. Although scenario 1 has the greatest economic benefit, while scenario 2 receives the least economic penalty (which will generate greater economic benefits), water consumption in scenario 1 exceeds the lower limit of total water use, which may lead to production reduction in a region because of water shortage. The economic benefit in scenario 2 is the lowest, which is not conducive to the sustainable economic development of Daxing district. In scenario 3, although the economic benefits and the penalties are both at a medium level, the water consumption is the smallest of the three scenarios, which means that scenario 3 can help to facilitate water preservation and at the same time, achieve high economic benefits. Therefore, scenario 3 is chosen as the basis for optimizing and adjusting planting structure. In scenario 3, when the target function takes the upper and lower limits, the water consumption is less than the total water consumption predicted for 2020, and the difference between the penalties is small. So the economic benefit is taken as the indicator for judgment and the optimal plan is scenario 3 with the objective function taking the value of the upper limit. By setting up scenarios for comparison analysis after solving the model, the optimal adjustment of planting structure for maximum economic benefits in Daxing district in 2020 is obtained: the planting area of grain crops should increase by $2,284.27$ ha compared with 2016; the planting area of fruits and vegetables should reduce by $13,801.20$ ha compared with 2016; The planting area of garden plots should increase by 13817.67 ha compared with 2016 .

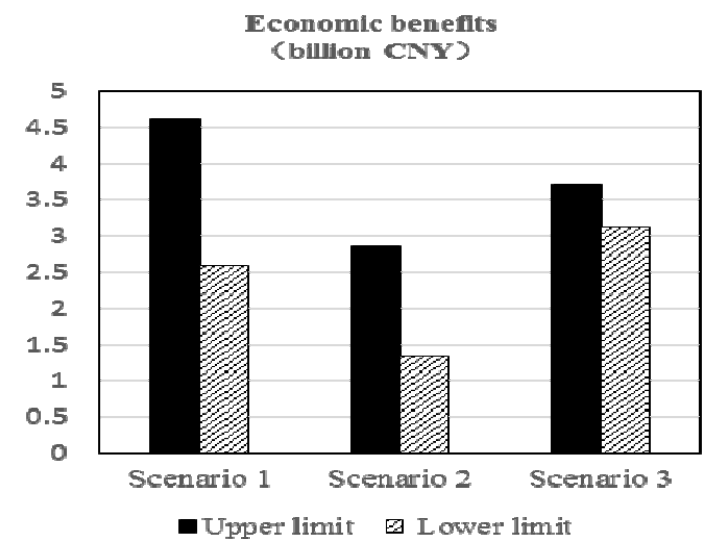




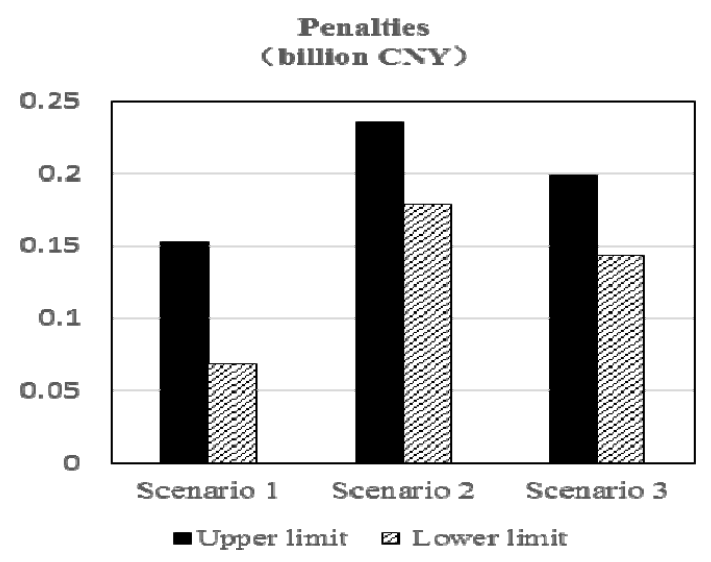

Water consumption

(million cublc meters)

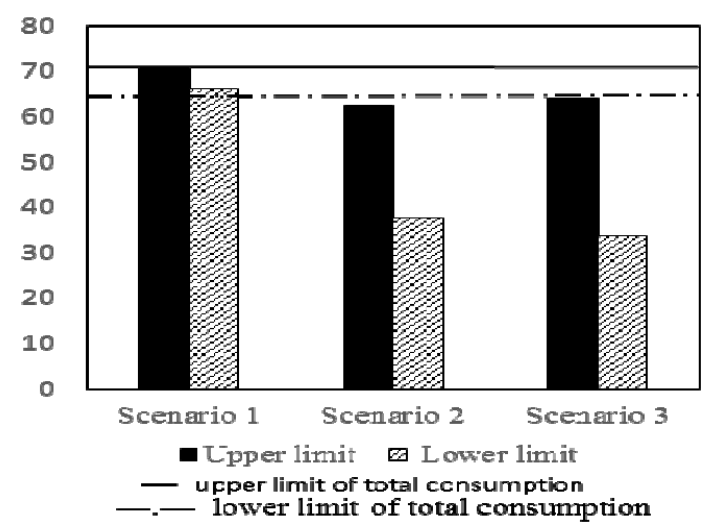

Figure 3 Comparison of economic benefits, penalties, and water consumption in different scenarios

The constraints of water quantity and area are imposed to Daxing district as a whole when the model is constructed, so the water consumption of each crop in each sub-district cannot be clearly constrained. Under this circumstance, in order to use the water resources more efficiently, some adjustments are made in the results of each crop in each sub-district under the condition that planting areas of the three crops are optimal respectively. The increased planting area of food crops is mainly concentrated in towns and villages such as Wei Shan,An Ding, Cai Yu and Chang Ziying; due to the fact that fruits and vegetables consume the largest amount of water, the areas where they are replaced by garden plots are mainly concentrated in the areas with seriously over-exploited underground water (see Figure 1). These adjustments can, to a certain degree, bring relief to the areas with seriously over-exploited underground water in Daxing district and improve the water efficiency. Figure 4 shows the adjusted planting structure drawn by Arcgis software. In summary, after optimization, the economic benefits of the three kinds of crops in Daxing district in 2020 is 3.71 billion CNY, an increase of 348 million CNY from 2016; the total water consumption is 64.17 million cubic meters, a decrease of 62.79 million cubic meters from 2016 .

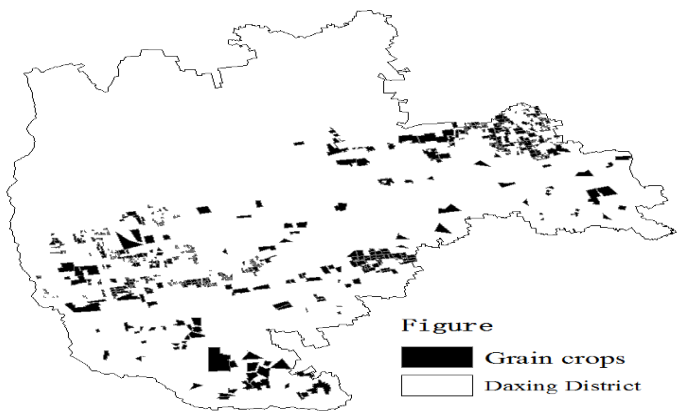

(Grain crops 2016)

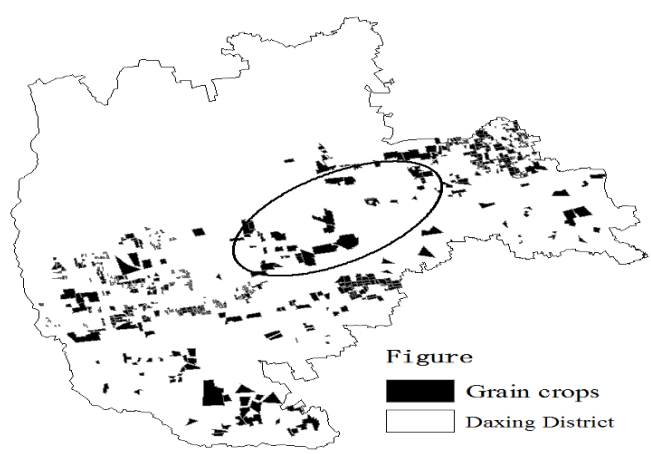

(Grain crops 2020)

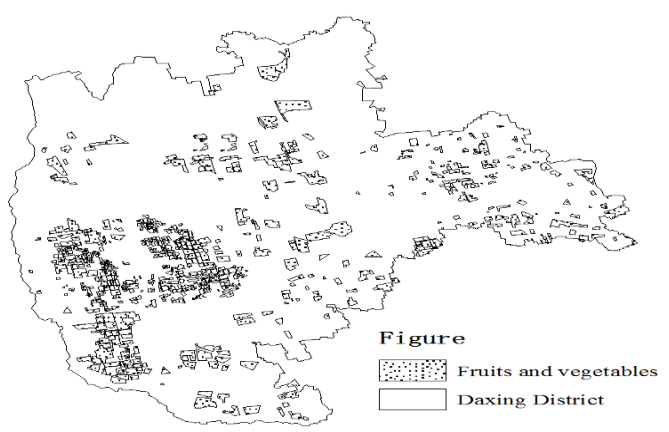

(Fruits and vegetables 2016)

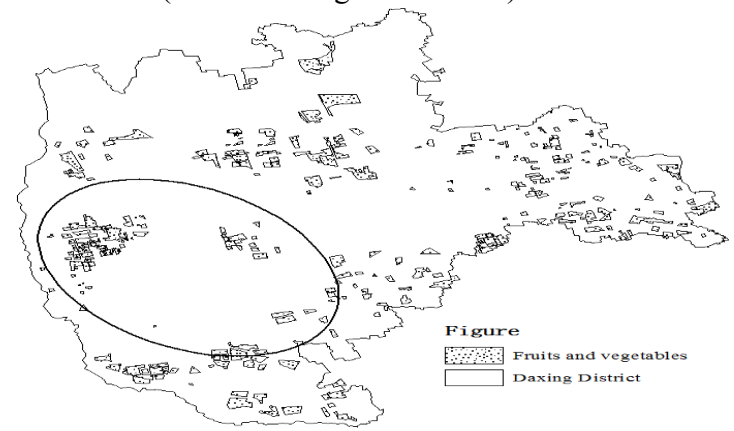

(Fruits and vegetables 2020)

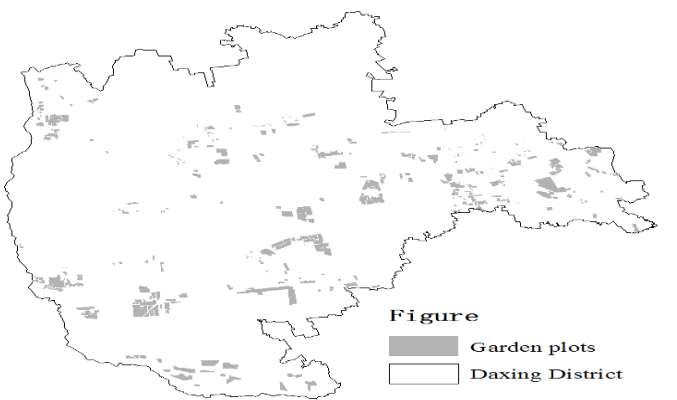

(Garden plots 2016) 


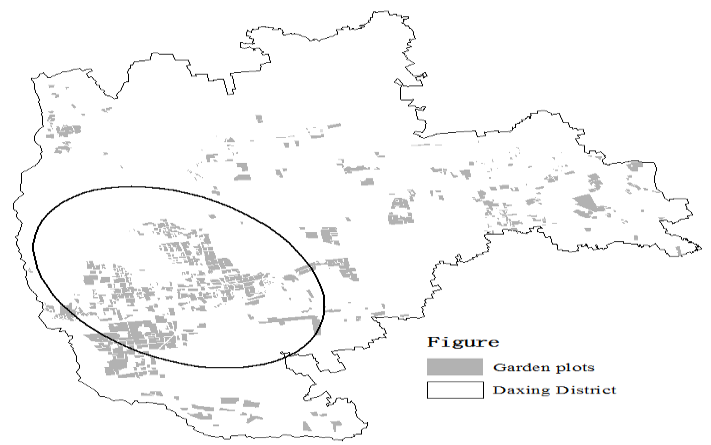

(Garden plots 2020)

Figure 4 Comparison of planting structure of grain crops, fruits and vegetables, and garden plots in Daxing district in 2016 and 2020

\section{Conclusion}

This paper constructs an inaccurate two-stage planning model, which not only solves the uncertainty problem of parameters, but also establishes an effective recourse relationship between economic benefits and penalties for failing to achieve the goals. The model is applied to optimize the planting structure in Daxing district, Beijing. By using gray GM (1.1), the population and agricultural water consumption of Daxing district in 2020 are forecasted, thus obtaining the food demand in Daxing district in 2020. Three scenarios are set up for comparative analysis. Ultimately, the optimal planning method is selected for optimizing the planting structure in Daxing district in 2020.

This paper introduces the inaccurate two-stage model into the planting structure optimization, and combines it with the gray GM (1.1) model so as to optimize the planting structure in 2020 . Results show that the model method is feasible for planting structure optimization, and can help to obtain relatively high economic benefits, and at the same time, save water resources. It provides, to some extent, decision-making support and a theoretical basis for optimizing and predicting the planting structure in similar areas with Daxing district. However, there are still some limits in this paper. Firstly, scenario settings are relatively simple. In future research, it is necessary to set more comprehensive scenarios so as to obtain more results for analysis. Secondly, the economic benefit is the only objective function, while social and ecological benefits are not taken into consideration. In addition, in the final adjustment stage, the only consideration is water consumption, while the balance between environmental resources of each sub-district is not taken into account, leading to limitations of results. Thirdly, the consideration for agricultural water use is not specific enough as there is no specific plan for allocating lacking or excess water when optimal efficiency is achieved. Finally, the basic data may fluctuate greatly for large-scale forecasting optimization, which does not meet the prediction criteria of the gray GM (1.1) model. Therefore, other models should be introduced to solve large-scale complex problems.
We gratefully acknowledge the financial support from the National Key R\&D Program of China (grant no. 2016YFC0401403) and NSFC (grant no. 51509269).

\section{References}

1. X.M. Li, Y.L. Cui, X.H. Xie. China Science paper. 3,530(2008).

2. Z.M. Xu. Water Resources Development Research. 5,44(2005).

3. S.Y. Wang. China Geographical Science. 6,70(1996).

4. R.L. Tang, C.Z. Guo, X.J. Dong. Journal of Hohai University(Natural sciences). 28,18(2000).

5. S.Y. Chen, J.Q. Ma,Z.W. Zhang. Journal of Dalian University of Technology. 43,12(2003).

6. X.P. Wu, H.J. Wu, Y. Zhuang. Chinese Journal of Agricultural Resources and Regional Planning. 32,16(2008).

7. M. Li, P. Guo. Transactions of the Chinese Society for Agricultural Machinery. 45,168(2014).

8. W. Li, Y.P. Li, C.H. Li. Agricultural Water Management. 97,1905(2010).

9. E. Mance, R. Saskatchewan. Water Resources Management. 28.10(2014).

10. G.H. Huang. Engineering Optimization. 26.79(1996).

11. G.H. Huang, B.W. Baetz, G.G. Party. Patry.Waste Management \& Research. 15.523(1997).

12. L.Z. Zhang. Numerical Modeling of groundwater flow in Daxing district based on FEFLOW. (China University of Geosciences,2009)

13. G.Q. Yang, L.F. Sun, X.M.E. Q. Huang, G. Ba. Beijing Water. 34(2014).

\section{Acknowledgments}

